\title{
Polyhydroxylated sulfated steroids derived from $5 \alpha$-cholestanes as antiviral agents against herpes simplex virus
}

\author{
Carlos A. Pujol ${ }^{1}$ - Claudia S. Sepúlveda ${ }^{1}$ - Victoria Richmond ${ }^{2} \cdot$ Marta S. Maier $^{2}$ • \\ Elsa B. Damonte ${ }^{1}$
}

Received: 3 November 2015/Accepted: 13 April 2016/Published online: 21 April 2016

(C) Springer-Verlag Wien 2016

\begin{abstract}
Twelve polyhydroxylated sulfated steroids synthesized from a $5 \alpha$-cholestane skeleton with different substitutions in C-2, C-3 and C-6 were evaluated for cytotoxicity and antiviral activity against herpes simplex virus (HSV) by a virus plaque reduction assay. Four compounds elicited a selective inhibitory effect against HSV. The disodium salt of $2 \beta, 3 \alpha$-dihydroxy- $6 E$-hydroximine-5 $\alpha$-cholestane-2,3-disulfate, named compound 7, was the most effective inhibitor of HSV-1, HSV-2 and pseudorabies virus (PrV) strains, including acyclovir-resistant variants, in human and monkey cell lines. Preliminary mechanistic studies demonstrated that compound 7 did not affect the initial steps of virus entry but inhibited a subsequent event in the infection process of HSV.
\end{abstract}

Keywords Herpes simplex virus - Antiviral activity · Polyhydroxylated sulfated steroids $\cdot 5 \alpha$-Cholestanes

During the past three decades, the marine environment has provided thousands of novel compounds with diverse and

Electronic supplementary material The online version of this article (doi:10.1007/s00705-016-2867-y) contains supplementary material, which is available to authorized users.

Elsa B. Damonte

edamonte@qb.fcen.uba.ar

1 Laboratorio de Virología, Departamento de Química Biológica- IQUIBICEN (CONICET-UBA), Facultad de Ciencias Exactas y Naturales, Universidad de Buenos Aires, Ciudad Universitaria, Pabellón 2, Piso 4, 1428 Buenos Aires, Argentina

2 Departamento de Química Orgánica- UMYMFOR (CONICET-UBA), Facultad de Ciencias Exactas y Naturales, Universidad de Buenos Aires, Ciudad Universitaria, Pabellón 2, Piso 3, 1428 Buenos Aires, Argentina important biological activities of pharmacological interest, including anticancer, antibacterial, antifungal, antiprotozoal and antiviral activities [1-5]. Some of them have served as lead compounds for obtaining new drugs that are currently in clinical use [6]. In relation to antiviral agents, the intensive use of existing drugs, especially in immunocompromised patients, has led to increased selection of resistant variants of important human pathogens, such as herpes simplex virus (HSV), human immunodeficiency virus (HIV) and human cytomegalovirus (HCMV) [7-9]. For this reason, new types of antiviral agents that are effective against resistant viral strains are in demand for public health, and marine drugs represent an interesting source of lead compounds.

Sulfated steroids are naturally occurring metabolites that can be isolated from a wide variety of marine organisms, in particular, sponges and echinoderms. Saponins, steroidal glycosides and polyhydroxysteroids with different degrees of sulfation, obtained from these marine sources have been described and have displayed a broad spectrum of biological properties, including antiviral activity [10-13]. Among pathogenic human viruses, HSV has been reported to be very susceptible to the inhibitory action of sulfated steroidal compounds [1, 11, 14]. HSV-1 and HSV-2, members of the genus Simplexvirus, subfamily Alphaherpesvirinae, are enveloped double-strand DNA viruses that can cause oral disease, keratoconjunctivitis, encephalitis and genital infections in humans, with different degrees of severity [15]. Most antiherpetic compounds in clinical use are nucleoside analogues, such as acyclovir, which is an excellent therapeutic drug [16]. To confront the frequent emergence of acyclovir-resistant HSV strains during longterm antiviral treatment in immunocompromised patients [17], the discovery of new non-nucleoside antiviral compounds is of significant interest. 
a

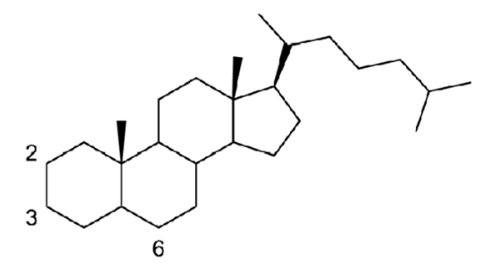

b

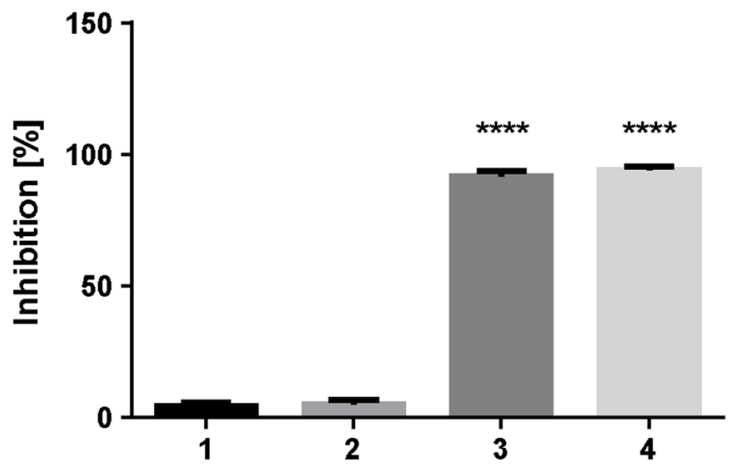

C Mock infected Virus control
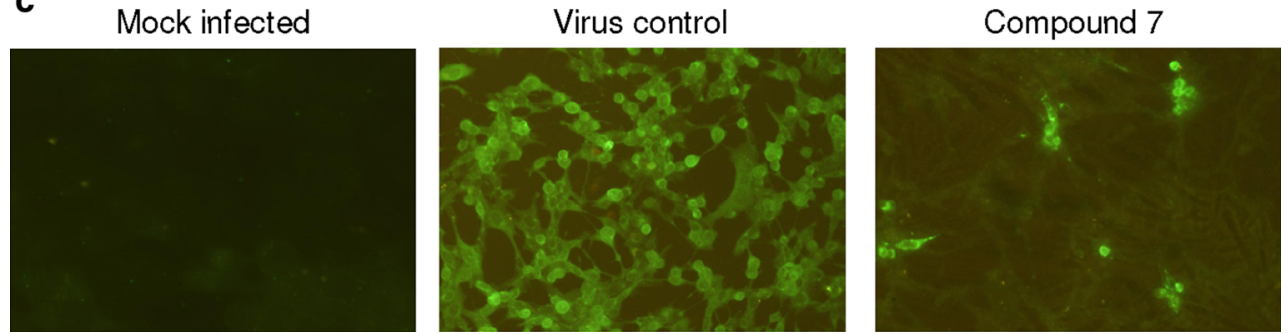

Fig. 1 Mode of anti-HSV activity of sulfated steroids. a) Chemical structure of the steroid skeleton and the three positions with substitutions. b) Effect on virus entry. Vero cells were infected with 50 PFU of HSV-1 strain F in a plaque assay under different treatment conditions with compound $7(25 \mu \mathrm{g} / \mathrm{ml})$. Treatment 1 , compound only during adsorption $\left(1 \mathrm{~h}\right.$ at $\left.4{ }^{\circ} \mathrm{C}\right)$; treatment 2 , compound only during penetration $\left(1 \mathrm{~h}\right.$ at $\left.37^{\circ} \mathrm{C}\right)$; treatment 3 , compound only after adsorption and penetration; treatment 4 , compound during and after adsorption and penetration. In all treatments, plaques were counted after 2 days of incubation at $37{ }^{\circ} \mathrm{C}$ and results are expressed as $\%$ inhibition of plaque number (mean of triplicate assays \pm standard deviation) in compound-treated cultures compared to untreated ones. Statistical analysis was performed with GraphPad Prism software and comparison of means was tested by one-way analysis of variance (ANOVA) with Dunnett's post-test (****, $p<0.0001)$. c) Effect on HSV-1 protein expression. Vero cells were mock infected or infected with HSV-1 strain F and incubated for $24 \mathrm{~h}$ in the absence or presence of compound 7. Immunofluorescence staining was carried out using anti-HSV-1 gD Ab. Magnification: 100x
Our research group has reported the antiviral activity against HSV of diverse sulfated steroids isolated from echinoderms from cold waters of the South Atlantic Ocean and their synthetic derivatives and analogs [18-20]. Preliminary structure-activity relationship studies showed the importance of sulfate groups in $\mathrm{C}-2(\beta)$ and $\mathrm{C}-3(\alpha)$ for antiviral activity of synthetic cholestanes [20]. The aim of the present study was to improve the antiviral effectiveness of these compounds by modification of the configuration of both sulfate groups as well as by substitution at position C-6 with hydroxyl, sulfate, keto or oxime groups.

Steroids were synthesized as described previously [2123]. The basic lead structure of the steroid skeleton is shown in Fig. 1a, and the different substitutions at positions 2, 3 and 6 of the derivatives are presented in Table 1. Stock solutions of the compounds at a concentration of $10 \mathrm{mg} / \mathrm{ml}$ were prepared in dimethylsulfoxide, and working solutions were obtained by appropriate dilution in culture medium.
The 12 sulfated polyhydroxysteroids were initially evaluated for cytotoxicity by the 3-(4,5-dimethylthiazol-2yl)-2,5-diphenyl tetrazolium bromide (MTT, SigmaAldrich) method in Vero cells grown in 96-well plates after $48 \mathrm{~h}$ of incubation with serial twofold dilutions of the compounds. Results were expressed as the $50 \%$ cytotoxic concentration $\left(\mathrm{CC}_{50}\right)$, the concentration of the compound required to reduce the MTT signal by $50 \%$ compared to controls. As shown in Table 1, the compounds displayed a wide range of cytotoxicity in Vero cells. Four of the twelve derivatives, compounds 7, 8, 9 and 11, did not affect Vero cell viability up to the maximum tested concentration of $100 \mu \mathrm{g} / \mathrm{ml}$. On the other hand, compounds 10 and 1 , both of which contain hydroxyl groups at C2 and C3, exhibited the highest cytotoxic effect. It is noteworthy that compound 8 , an epimer of compound 10 in C-6, lacked cytotoxicity at the tested concentrations, suggesting an apparent influence of the $\mathrm{OH}$ group in $\mathrm{C}-6(\alpha)$ on the cytotoxic properties of these two steroids. 
Table 1 Cytotoxicity and antiviral activity of steroids against HSV-1

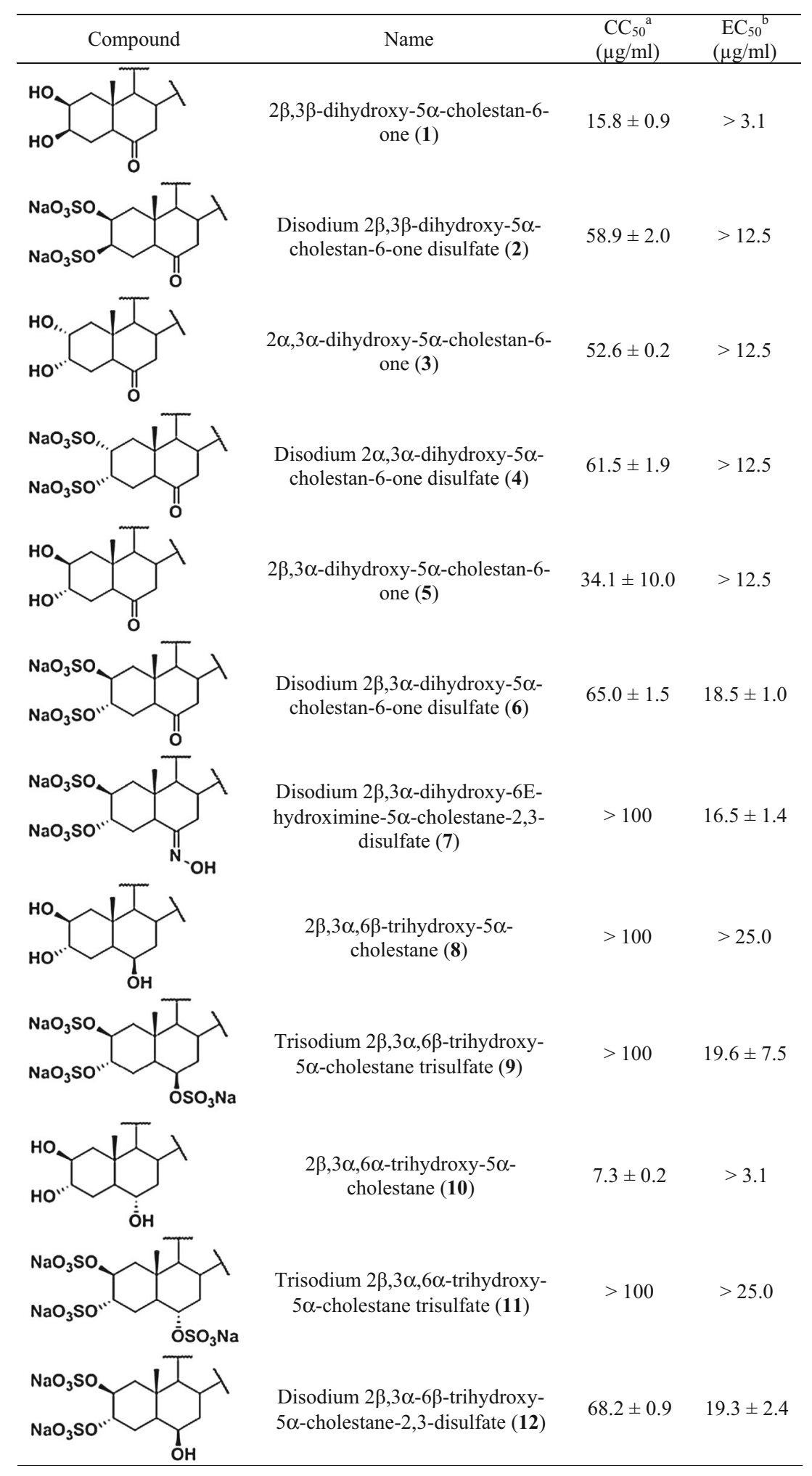

a $50 \%$ Cytotoxic concentration: concentration required to reduce Vero cell viability by $50 \%$

b $50 \%$ Effective concentration: concentration required to reduce HSV-1 plaque number in Vero cells by $50 \%$

Values are the mean from triplicate independent tests \pm standard deviation 
Next, the antiviral activity against HSV-1 was tested by plaque reduction assay in Vero cell monolayers grown in 24-well microplates and infected with about $50 \mathrm{PFU}$ of HSV-1 strain F per well in the absence or presence of the steroids. Each compound was assayed at serial twofold concentrations at least fourfold lower than the $\mathrm{CC}_{50}$ in order to assess selectivity of the inhibitory effect. After adsorption for $1 \mathrm{~h}$, the residual inoculum was replaced by MEM containing $0.7 \%$ methylcellulose and the corresponding dose of compound. Plaques were counted after 2 days of incubation, and the $50 \%$ effective concentration $\left(\mathrm{EC}_{50}\right)$ was calculated as the concentration required to reduce the number of virus plaques by $50 \%$ in the compound-treated cultures compared with the untreated ones. Four out of the twelve steroids, compounds 6, 7,9 and 12, were inhibitors of HSV-1 cytopathogenicity (Table 1). A representative graph of the dose-dependent reduction in HSV-1 plaque number by compound 7 (the most active inhibitor) is shown in Supplementary Fig. 1. The average plaque size after infection with HSV-1 in the presence and absence of compound 7 was determined by measuring the diameter of all of the isolated plaques present in four wells of infected control cells and infected cells treated with $15 \mu \mathrm{g}$ of the compound per $\mathrm{ml}$, using Image-Pro Plus 4.5.0 software. Although an apparent reduction in plaque size was observed (values of mean diameter were $0.104 \pm 0.026 \mathrm{~mm}$ for control HSV-1 plaques vs. $0.079 \pm 0.015 \mathrm{~mm}$ for HSV-1 plaques produced in treated cells), the difference was not significant according to overlapping of values \pm standard deviation. From the data in Table 1, it can be concluded that sulfation is required for antiviral activity, since non-sulfated compounds were not active. However, certain requisites must be fulfilled to assess the antiviral properties of these steroids. Among the sulfated compounds, the combination of sulfate groups at positions $C-2(\beta)$ and $C-3(\alpha)$ and a keto, oxime or $\beta$-hydroxyl (free and sulfated) group at C-6, corresponding to the four active compounds, appears also to be favourable for antiviral activity. The presence of only one of these groups, as occurs in the other sulfated compounds, appeared to be insufficient to allow an inhibitory effect against HSV-1 infection.

Since steroid 7 (disodium 2 $\beta, 3 \alpha$-dihydroxy- $6 E$-hydroximine-5 $\alpha$-cholestane-2,3-disulfate) was the most effective and safe steroid against HSV-1 strain F, this compound was chosen to further characterize the antiviral properties of this type of polyhydroxylated sulfated steroids. To evaluate the spectrum of anti-herpetic activity of compound 7, a virus plaque reduction assay was performed in Vero cells against HSV-2, strain G, and the TK ${ }^{-}$strain B2006 of HSV1 , which is resistant to acyclovir. Pseudorabies virus (PrV), also known as suid herpesvirus 1 (SuHV-1), which is the causative agent of Aujeszky's disease in swine and a
Table 2 Spectrum of antiviral activity of compound 7

\begin{tabular}{lll}
\hline Virus & Cell line & $\mathrm{EC}_{50}^{\mathrm{a}}(\mu \mathrm{g} / \mathrm{ml})$ \\
\hline HSV-1 strain B2006 & Vero & $19.5 \pm 1.1$ \\
HSV-2 strain G & Vero & $17.9 \pm 0.4$ \\
PrV strain RC79 & Vero & $17.2 \pm 0.6$ \\
HSV-1 strain F & A549 & $16.7 \pm 1.5$ \\
JUNV strain IV4454 & Vero & $>25$ \\
DENV-2 strain NGC & Vero & $>25$
\end{tabular}

a $50 \%$ Effective concentration: concentration required to reduce plaque number in Vero cells by $50 \%$

Values are the mean from triplicate independent tests \pm standard deviation

prominent viral pathogen in veterinary medicine [24], was also included in the antiviral testing as a member of another genus in the subfamily Alphaherpesvirinae, the genus Varicellovirus. The compound displayed similar activity against HSV-1, HSV-2 and PrV, and also against the acyclovir-resistant variant of HSV-1 (Table 2). Interestingly, these results suggest the possibility of employing steroidal agents like compound 7 as an alternative drug against acyclovir-resistant HSV strains. Furthermore, the activity of compound 7 was also evaluated against HSV by plaque reduction assay in another cell type, the human cell line A549, under the same experimental conditions employed in Vero cells. The susceptibility to the inhibitory action of steroid 7 was similar in both cell systems, with $\mathrm{EC}_{50}$ values of $16.7 \pm 1.5 \mu \mathrm{g} / \mathrm{ml}$ (Table 2) and $16.5 \pm 1.4 \mu \mathrm{g} / \mathrm{ml}$ (Table 1) in A549 and Vero cells, respectively. Thus, the anti-herpetic action of the steroid appeared to be independent of the host cell.

The activity of steroid 7 against HSV was assessed in Vero cells using another assay, the virus yield inhibition method, as previously described [25]. Briefly, cells were infected with HSV-1 strain F at a multiplicity of infection (MOI) of $0.1 \mathrm{PFU} / \mathrm{cell}$ in the presence of different concentrations of the compound in the range of $0-25 \mu \mathrm{g} / \mathrm{ml}$. After $24 \mathrm{~h}$ of infection, virus yields were titrated by plaque formation, and the $\mathrm{EC}_{50}$ was calculated as the compound concentration able to reduce virus yield by $50 \%$ in treated cultures. In this assay, HSV-1 was also sensitive to the antiviral action of compound 7 , with an $\mathrm{EC}_{50}$ of $20.0 \pm 3.0 \mu \mathrm{g} / \mathrm{ml}$. Thus, the antiviral action of compound 7 was not mainly affected by the type of antiviral test used. It should be noted that the viral yield reduction method is a more stringent measure of the potency of an antiviral compound than the plaque reduction assay because the multiplicity of infection is higher in the first method ( 0.1 vs. $0.0005 \mathrm{PFU} / \mathrm{cell}$ ). To confirm the lack of dependence of steroid 7 on the dose of the infecting virus inoculum, a virus yield inhibition assay at high MOI (10 PFU/cell) was 
performed. Under these experimental conditions, almost all of the cells have the chance to be infected by input virus. The $\mathrm{EC}_{50}$ at high MOI was $21.4 \pm 2.5 \mu \mathrm{g} / \mathrm{ml}$, demonstrating the ability of compound 7 to block HSV infection even in the presence of high initial virus doses.

The antiviral activity of compound 7 was also assayed against other human pathogenic viruses, including Junín virus (JUNV), a member of the family Arenaviridae and the agent of Argentine hemorrhagic fever [26], and dengue virus (DENV), a flavivirus agent of dengue fever and dengue hemorrhagic fever in humans that is transmitted through the bite of infected Aedes mosquitoes and is at present the most widespread arthropod-borne virus in the world [27]. Both hemorrhagic-fever-causing viruses lack a specific and safe therapy for treatment. No reduction in JUNV and DENV plaque number was observed in a plaque inhibition assay performed in Vero cells using up to the maximum non-cytotoxic concentration according to cytotoxicity data (Table 1 ). Therefore, the $\mathrm{EC}_{50}$ for both viruses is given in Table 2 as $>25 \mu \mathrm{g} / \mathrm{ml}$. Since DENV and JUNV are enveloped viruses like $\mathrm{HSV}$ and PrV, these steroids do not appear to interfere with replication of enveloped viruses in general but instead have a more restricted antiviral spectrum.

As a first approach to studying the mechanism of action of the most active compound on HSV-1, the possibility that it acted either by direct interaction with the virus particle or through a blockade in virus multiplication during the infectious process was investigated. To investigate the potential interaction of compound 7 with the virus particle, leading to infectivity inactivation, a virucidal assay was performed. To this end, a virus suspension containing $6 \times 10^{5}$ PFU of HSV-1 strain $\mathrm{F}$ was exposed for $1 \mathrm{~h}$ at $37{ }^{\circ} \mathrm{C}$ to various concentrations of compound, and samples were then chilled and diluted to determine residual infectivity by plaque formation. The sample dilution effectively reduced the drug concentration to be incubated with the cells by at least 100 -fold to ensure that the titer reduction was only due to cell-free virion inactivation. The $50 \%$ virucidal concentration $\left(\mathrm{VC}_{50}\right)$, defined as the concentration required to inactivate virions by $50 \%$, was then calculated. Compound 7 had a weak inactivating effect on HSV-1 virions with a $\mathrm{VC}_{50}$ value of $68.1 \pm 6.3 \mu \mathrm{g} / \mathrm{ml}$, a value more than 4-fold higher than the concentration required to reduce virus plaques when the compound was added at the time of infection (Table 1). These results confirmed that the inhibitory effect detected by the plaque reduction assay was mainly due to interference with some step of the HSV-1 multiplication cycle and not by virucidal action.

Virus entry is the initial stage of the virus life cycle, including the adsorption of virions to the cell receptor and the subsequent penetration into the cell. To estimate the effect of compound 7 on virus entry, a plaque reduction assay was performed under different treatment conditions as described previously [28]. Briefly, Vero cells were infected with 50 PFU of HSV-1 strain F per well and treated with compound $7(25 \mu \mathrm{g} / \mathrm{ml})$ as follows: 1) Treatment during adsorption: cells were infected in the presence of compound, and after $1 \mathrm{~h}$ of adsorption at $4{ }^{\circ} \mathrm{C}$, both the compound and unadsorbed virus were removed and cell cultures were overlaid with plaquing medium without compound. 2) Treatment during penetration: cells were infected in the absence of compound and after $1 \mathrm{~h}$ of adsorption at $4{ }^{\circ} \mathrm{C}$, the cells were washed with cold PBS and further incubated for $1 \mathrm{~h}$ at $37{ }^{\circ} \mathrm{C}$ in medium containing the compound. The cells were then washed with cold PBS, and citric buffer $(40 \mathrm{mM}$ citric acid, $10 \mathrm{mM}$ $\mathrm{KCl}, 135 \mathrm{mM} \mathrm{NaCl}, \mathrm{pH}$ 3.0) was added to remove adsorbed, non internalized virions. After $1 \mathrm{~min}$, cells were washed again with PBS and covered with plaquing medium without compound. 3) Treatment after adsorption and penetration: cells were infected in the absence of compound and after $1 \mathrm{~h}$ at $4{ }^{\circ} \mathrm{C}$ and $1 \mathrm{~h}$ at $37^{\circ} \mathrm{C}$, inocula were removed, and the cells were further incubated with plaquing medium containing the compound. 4) Treatment during and after adsorption and penetration: cells were infected in the presence of compound, and after $1 \mathrm{~h}$ at $4{ }^{\circ} \mathrm{C}$ and $1 \mathrm{~h}$ at $37^{\circ} \mathrm{C}$, cells were overlaid with plaquing medium containing the compound. In all treatments, virus plaques were counted after 2 days of incubation at $37^{\circ} \mathrm{C}$. When the plaque reduction assay was performed after including the compound only during the period of virus adsorption $\left(1 \mathrm{~h}\right.$ at $\left.4{ }^{\circ} \mathrm{C}\right)$ or penetration $\left(1 \mathrm{~h}\right.$ at $\left.37^{\circ} \mathrm{C}\right)$ and omitting it from the plaquing medium after virus entry, no significant reduction in the number of virus plaques was detected (Fig. 1b). By contrast, treatment with the compound only after virus adsorption and penetration was as effective for reducing the plaque number as treatment during the whole incubation period (Fig. 1b), indicating that compound 7 does not prevent HSV-1 entry into the cell.

Finally, the effect of compound 7 on virus infection was studied by indirect immunofluorescence assay. Vero cells grown on coverslips were infected with HSV-1 strain F at a multiplicity of infection of 0.1 and treated or not with the compound for $24 \mathrm{~h}$. The cells were then fixed in methanol for $15 \mathrm{~min}$ at $-20{ }^{\circ} \mathrm{C}$, and cytoplasmic immunofluorescence staining was carried out by using a mouse monoclonal antibody that is reactive against HSV-1 glycoprotein D (gD) (Santa Cruz, USA), followed by fluorescein isothiocyanate (FITC)-goat anti-mouse IgG (Sigma Aldrich Co, USA). After a final washing with PBS, cells were mounted in a glycerol solution containing 1,4-diazabicyclo[2]octane (DABCO). Control infected cells exhibited a regular intense staining distributed throughout the intracellular space in most cells of the culture, whereas the amount of 
cells showing cytoplasmic fluorescence for $\mathrm{gD}$ was drastically reduced after treatment with compound 7 (Fig. 1c).

In conclusion, polyhydroxylated sulfated steroids derived from $5 \alpha$-cholestanes show interesting and selective antiviral properties against HSV. According to structureactivity analysis, the presence of sulfate groups in positions $\mathrm{C}-2(\beta)$ and $\mathrm{C}-3(\alpha)$ together with a keto, oxime or $\beta$-hydroxyl (free or sulfated) group at position C-6 appeared to be required for an effective antiviral activity. Compound 7, the most effective steroid, was active against HSV-1, HSV2, $\mathrm{PrV}$ and $\mathrm{TK}^{-} \mathrm{HSV}$ variants resistant to acyclovir, the drug clinically used for treatment of herpetic infections. Thus, this class of sulfated steroid is a promising lead candidate for alternative therapy in HSV-infected immunocompromised patients, a population prone to select for drug-resistant virus after a prolonged treatment with acyclovir [17]. Furthermore, the inhibitory activity of the steroid was independent of the MOI and the antiviral assay used for testing.

Mechanistic studies demonstrated that virus entry into the host cell was not altered by compound 7. Other sulfated substances, including steroidal compounds and polysaccharides, have been described as potent anti-HSV agents that inhibit the initial events of virus attachment and penetration into the cell by interfering with the interaction of an external virus glycoprotein with heparan sulfate residues that act as virus receptors on the cell membrane [14, 29, 30]. It is well established that the antiviral effectiveness of polysulfates is dependent on their degree of sulfation, which determines the negative charge of the molecule [31]. Although compound 7 contains two sulfate groups, at positions $\mathrm{C} 2$ and $\mathrm{C} 3$, the negative charge density is probably not enough to interfere with the initial HSV glycoprotein-heparan sulfate interaction. Instead, the anti-HSV activity of the steroid appears to be exerted after initial virus entry into the cell, affecting post-penetration events during the intracellular virus replication or cell-to-cell virus spread. Further experiments are required to fully elucidate the antiviral target of this sulfated steroid

\section{Compliance with ethical standards}

Funding This work was funded by grants from Agencia Nacional para la Promoción Científica y Tecnológica (ANPCyT, grant number 0506), Consejo Nacional de Investigaciones Científicas y Técnicas (CONICET, grant number 11220090100071), and Universidad de Buenos Aires (grant numbers 00448 and 00404), Argentina. CSS, MSM and EBD are Research Members of CONICET.

Conflict of interest The authors declare that they have no conflict of interest.

Ethical approval This article does not contain any studies with human participants or animals performed by any of the authors.

\section{References}

1. Vo T-S, Ngo D-H, Ta QV, Kim S-K (2011) Marine organisms as a therapeutic source against herpes simplex virus infection. Eur J Pharm Sci 44:11-20

2. Cheung RCF, Wong JH, Pan WL, Chan YS, Yin CM, Dan XL, Wang HX, Fang EF, Lam SK, Ngai PHK, Xia LX, Liu F, Ye XY, Zhang GQ, Liu QH, Sha O, Lin P, Ki C, Bekhit AA, Bekhit AE, Wan DCC, Ye XJ, Xia J, Ng TB (2014) Antifungal and antiviral products of marine organisms. Appl Microbiol Biotechnol 98:3475-3494

3. Newman DJ, Cragg GM (2014) Marine-sourced anti-cancer and cancer pain control agents in clinical and late preclinical development. Mar Drugs 12:255-278

4. García M, Monzote L (2014) Marine products with anti-protozoal activity: a review. Curr Clin Pharmacol 9:258-270

5. Dang VT, Benkendorff K, Green T, Speck P (2015) Marine snails and slugs: a great place to look for antiviral drugs. J Virol 89:8114-8118

6. Yasuhara-Bell J, Lu Y (2010) Marine compounds and their antiviral activities. Antiviral Res 86:231-240. doi:10.1016/j.anti viral.2010.03.009

7. Megens S, Laethem KV (2013) HIV-1 genetic variation and drug resistance development. Expert Rev Anti Infect Ther 11:1159-1178

8. Andrei G, Snoeck R (2013) Herpes simplex virus drug-resistance: new mutations and insights. Curr Opin Infect Dis 26:551-560

9. Komatsu TE, Pikis A, Naeger LK, Harrington PR (2014) Resistance of human cytomegalovirus to ganciclovir/valganciclovir: a comprehensive review of putative resistance pathways. Antiviral Res 101:12-25

10. Rudi A, Yosief T, Loya S, Hizi A, Schleyer M, Kashman Y (2001) Clathsterol, a novel anti-HIV-1 RT sulfated sterol from the sponge Clathria species. J Nat Prod 64:1451-1453

11. Peng Y, Zheng J, Huang R, Wang Y, Xu T, Zhou X, Liu Q, Zeng F, Ju H, Yang X, Liu Y (2010) Polyhydroxy steroids and saponins from China sea starfish Asterina pectinifera and their biological activities. Chem Pharm Bull 58:856-858

12. Gong KK, Tang XL, Zhang G, Cheng CL, Zhang XW, Li PL, Li GQ (2013) Polyhydroxylated steroids from the South China Sea soft coral Sarcophyton sp. and their cytotoxic and antiviral activities. Mar Drugs 11:4788-4798

13. Kim SK, Himaya SW (2012) Triterpene glycosides from sea cucumbers and their biological activities. Adv Food Nutr Res 65:297-319

14. Guimaraes TR, Quiroz CG, Rigotto C, Oliveira SQ, Almeida MTR, Bianco EM, Moritz MIG, Carraro JL, Palermo JA, Cabrera G, Schenkel EP, Reginatto FH, Simoes CMO (2013) Anti-HSV-1 activity of halistanol sulfate and halistanol sulfate $\mathrm{C}$ isolated from Brazilian marine sponge Petromica citrina (Demospongiae). Mar Drugs 11:4176-4192

15. Whitley RJ, Roizman B (2009) Herpes simplex viruses. In: Richmann DD, Whitley RJ, Hayden FG (eds) Clinical Virology, 3rd edn. ASM Press, Washington, pp 409-436

16. Brady RC, Bernstein DI (2004) Treatment of herpes simplex virus infections. Antiviral Res 61:73-81

17. Piret J, Boivin G (2011) Resistance of herpes simplex viruses to nucleoside analogues: mechanisms, prevalence and management. Antimicrob Agents Chemother 55:459-472

18. Comin MJ, Maier MS, Roccatagliata AJ, Pujol CA, Damonte EB (1999) Evaluation of the antiviral activity of natural sulfated polyhydroxysteroids and their synthetic derivatives and analogs. Steroids 64:335-340

19. Maier MS, Roccatagliata AJ, Kuriss A, Chludil H, Seldes AM, Pujol CA, Damonte EB (2001) Two new cytotoxic and virucidal 
trisulfated triterpen glycosides from the Antarctic sea cucumber Staurocucumis liouvillei. J Nat Prod 64:732-736

20. Garrido Santos GA, Murray AP, Pujol CA, Damonte EB, Maier MS (2003) Synthesis and antiviral activity of sulfated and acetylated derivatives of $2 \beta, 3 \alpha$-dihydroxy-5 $\alpha$-cholestane. Steroids 68:125-132

21. Richmond V, Garrido Santos G, Murray AP, Maier MS (2011) Synthesis and acetylcholinesterase inhibitory activity of $2 \beta, 3 \alpha-$ disulfoxy-5 $\alpha$-cholestan-6-one. Steroids 76:1160-1165

22. Richmond V, Murray AP, Maier MS (2013) Synthesis and acetylcholinesterase inhibitory activity of polyhydroxylated sulfated steroids: Structure/activity studies. Steroids 78:1141-1147

23. Richmond V, Careaga VP, Sacca P, Calvo JC, Maier MS (2014) Synthesis and cytotoxic evaluation of four new $6 E$-hydroximinosteroids. Steroids 84:7-10

24. Müller T, Hahn EC, Tottewitz F, Kramer M, Klupp BG, Mettenleiter TC, Freuling C (2011) Pseudorabies virus in wild swine: a global perspective. Arch Virol 156:1691-1705

25. Carlucci MJ, Ciancia M, Matulewicz MC, Cerezo AS, Damonte EB (1999) Antiherpetic activity and mode of action of natural carrageenans of diverse structural types. Antiviral Res 43:93-102
26. García CC, Sepúlveda CS, Damonte EB (2011) Novel therapeutic targets for arenavirus hemorrhagic fevers. Future Virol 6:27-44

27. Guzmán MG, Harris E (2015) Dengue. Lancet 385:453-465

28. Mandal P, Mateu CG, Chattopadhyay K, Pujol CA, Damonte EB, Ray B (2007) Structural features and antiviral activity of sulphated fucans from the brown seaweed Cystoseira indica. Antiviral Chem Chemother 18:153-162

29. Damonte EB, Matulewicz MC, Cerezo AS (2004) Sulfated seaweed polysaccharides as antiviral agents. Curr Med Chem 11:2399-2418

30. Wang W, Wang S-X, Guan HS (2012) The antiviral activities and mechanisms of marine polysaccharides: an overview. Mar Drugs 10:2705-2816

31. Ghosh T, Chattopadhyay K, Marschall M, Karmakar P, Mandal P, Ray B (2009) Focus on antivirally active sulfated polysaccharides: From structure-activity analysis to clinical evaluation. Glycobiology 19:2-15 